\title{
NA ERA GOURMET: UM ESTUDO SOBRE GESTÃO DE CAIXA E GESTÃO DE RISCOS DA PRODUÇÃO DE FARINHAS SABORIZADAS
}

\section{ARTIGO ORIGINAL}

ARAÚJO, Jamille Carla Oliveira ${ }^{1}$

PIANCHÃO, Marcela Maria De Sousa ${ }^{2}$

BARRETO, Norma Katharina ${ }^{3}$

SARDEIRO, Luciana Da Silva Moraes ${ }^{4}$

ARAÚJO, Jamille Carla Oliveira. Et al. Na era gourmet: Um estudo sobre gestão de caixa e gestão de riscos da produção de farinhas saborizadas. Revista Científica Multidisciplinar Núcleo do Conhecimento. Ano 04, Ed. 10, Vol. 06, pp. 131-153. Outubro de 2019. ISSN: 2448-0959, Link de acesso: https://www.nucleodoconhecimento.com.br/contabilidade/na-era-gourmet

\section{RESUMO}

O presente estudo objetivo analisar como é realizada a gestão de caixa e de riscos na produção da farinha saborizada no município de Bragança, pertencente a região do Caeté, no Estado do Pará. Partindo de informações contidas nos dados e documentos

${ }^{1}$ Mestre em Administração, MBA Gestão contábil, perícia, auditoria e controlaria, Bacharel em Ciências Contábeis.

${ }^{2}$ Discente do curso de Ciências Contábeis e Administração da Escola Superior Madre Celeste- ESMAC.

${ }^{3}$ Discente do curso de Ciências Contábeis da Universidade Federal Rural da Amazônia (UFRA).

${ }^{4}$ Mestre em Planejamento e Gestão Ambiental, Especialista em Educação Ambiental, Especialista em Auditoria e Perícia Contábil. Atualmente é Professora Assistente na Universidade Federal Rural da Amazônia - UFRA. 
fornecidos pela Empresa de Assistência Técnica e Extensão Rural do Estado do Pará (EMATER) e por meio de informações coletadas in lócus, observou-se todas as etapas de produção, e, assim, foram realizadas entrevistas com os proprietários de pequenos empreendimentos econômicos que são formados por três micro empreendimentos de farinha pertencentes ao município de Bragança, no Pará. Estas empresas de produção são formadas por seis famílias que compartilham a mesma casa de torrefação de farinha, forno de escaldamento e grolagem, executando, dessa forma, a produção em conjunto e compartilhando rendimentos que são distribuídos conforme a quantidade produzida, e, também, vendida, que compõe o caixa de cada micro empreendimento econômico. Os riscos operacionais no processo de produção são atribuídos por duas situações: a primeira por pular etapas de produção perdendo a qualidade da farinha e a segunda atribuída pelo não venda da produção exigindo soluções imediatas para garantir o sustento das famílias locais. Desta forma, parte-se da seguinte questão norteadora: Como estas empresas vem realizando a gestão de caixa e gestão de risco da produção de farinhas saborizadas na região do Caeté, no Estado do Pará? Os resultados informam que existe uma gestão de caixa condizente com a realidade local, entretanto, necessita-se de um olhar voltado para tomada de decisão e planejamento, evidenciando, nesse ponto, o risco operacional atribuído a gestão de resultados.

Palavras-Chaves: Farinha saborizada, gestão de caixa, risco operacional.

\section{INTRODUÇÃO}

A cultura da mandioca encontra-se muito intensa na região do Caeté, no município de Bragança, localizado no Estado do Pará, o qual, ao longo dos anos, vem desenvolvendo uma ampla diversidade de produtos derivados da raiz, e, assim, exerce um papel importante tanto na dieta alimentar humana, como na animal (Bragança, 2000; Nassar, 2006; EMBRAPA, 2009). No ano de 2015, foi estimado que a produção brasileira deteve $10,4 \%$ da produção mundial da cultura da mandioca, contribuindo, dessa forma, para que o Brasil obtivesse lugar de destaque, tornandose, nesse contexto, o quarto maior produtor de mandioca do mundo (Brasil, 2011; IBGE, 2014).Na produção local, sabe-se que a composição mais essencial da 
mandioca é a sua raiz, e, assim, é utilizada in natura para a obtenção do que Bezerra (2006) e Chisté (2006) denominam de subprodutos. Os mais frequentes são a farinha seca, d’água, a fécula, o tucupi e a farinha de tapioca.

Além disso, a cultura, ao longo dos anos, tem grande potencial de transformação (Cardoso, Souza, 2000; Batalha, Silva, 2009), principalmente ao se tratar da farinha de mandioca, da classe d'agua, pois passou a ter sabores regionais, classificando-se como gourmet, por exemplo, de farinha: com jambu, com jambu e charque, com açaí, beterraba, e, por fim, com aviú (micro camarão). Essa produção é desenvolvida por três empresas produtivas que são únicas produtoras locais, e, dessa forma, vem alcançando mercado pelo critério de inovação produtiva. Deste modo, essas organizações produtivas vêm gerenciando seus caixas de acordo com suas vendas, o que perfaz a necessidade de uma boa gestão de seus recursos para que o processo de tomada de decisão seja sustentado a partir de informações precisas e de acordo com a realidade empresarial (Hall et al, 2012; Silva Filho et al, 2015; Vieira, 2017; Oliveira; Gorh, 2018).

A literatura aponta que para se obter eficácia no processo de gestão é importante realizar avaliações frequentes para que seja possível medir a qualidade dos dados que são repassados aos gestores responsáveis pelas tomadas de decisões diárias (Davenport, 2002; Catelli, 2001; Fernandes et al, 2012; Padoveze, 2012, 2015). Contudo, a adesão às metodologias e ferramentas contábeis subsidia os dados que fornecem uma visão mais ampla aos gestores para que esses tenham uma atitude mais condizente aos objetivos e metas empresariais diante da apuração e destinação de caixas, para que seja evitado o risco operacional atribuído pela má gestão que refletem em resultados presentes e futuros (Marion, 2003; Ribeiro; Freire, Barella, 2012; Rodrigues; Elias; Campos, 2014; Silva Filho et. al. 2015).

Desta forma, o estudo se fundamenta na avaliação da cadeia produtiva da mandioca em face à produção de novos subprodutos e à observação da obtenção, organização, planejamento dos recursos financeiros obtidos e capazes de definir a continuidade organizacional (Dias, Vasconcellos, 2011). Para os estudos de Gold, Seuring e Beske (2010) e Baraldi, Gressetvold e Harrison (2012), a relação entre as empresas está 
ligada às fases de combinação, recombinação e desenvolvimento de recursos que se manifestam na interação entre as organizações. Permite-se, dessa forma, o fortalecimento desses empreendimentos, pois eles se tornam competitivos. Esse detalhamento pode servir de base para novos produtores, e, assim, são relevantes para o conhecimento da gestão de caixas e dos riscos atribuídos pela gestão e a própria competitividade de mercado (Fietz; Costa; Beuren, 2007; Porter, 2008; Dias, 2010; Nascimento, 2015).

Assim, esse estudo tem como objetivo analisar como são realizados os processos voltados à gestão de caixa e à gestão dos riscos de produção da farinha saborizada no município de Bragança, pertencente à região do Caeté, no Estado do Pará. Por meio disso, a pesquisa possui a seguinte questão norteadora: Como as empresas produtoras de farinhas saborizadas do município de Bragança, na região do Caeté, Estado do Pará, realizam a gestão de caixa e gestão de risco de sua produção? Além das premissas iniciais, a pesquisa está estruturada a partir de um referencial teórico que abrange a cadeia produtiva da mandioca. Em seguida, foram discutidos os aspectos e a relevância da gestão de caixa e de risco operacional; os conceitos metodológicos que deram forma à pesquisa; a análise dos dados e a conclusão para responder à questão norteadora do estudo.

\section{REFERENCIAL TEÓRICO}

\subsection{CADEIRA PRODUTIVA DA MANDIOCA}

A mandioca é cultivada em mais de 80 países da Américas, África e Ásia, em áreas tropicais e subtropicais (Viletti; Junkes; Groff, 2015). No Brasil, a produção da mandioca representa mais de 15\% da produção mundial, segundo Alves e Silva, 2003. Isto se dá devido a mandioca possuir caraterísticas favoráveis para seu cultivo pela agricultura familiar, sendo aproveitada para alimentação humana e animal (Bezerra, 2006). Na alimentação humana é utilizada, diretamente, no consumo alimentar, pois compõe pratos tradicionais e até a merenda escolar, consumida na forma de farinha, goma, beiju e biscoitos de goma (Bragança, 2000; Alves; Modesto, 2013; Viletti et. al. 2015). Foi introduzida na alimentação pelo seu fator nutritivo por diversas classes 
sociais na região Norte e Nordeste (BEZERRA, 2006). Como ração animal, a mandioca é aproveitada a partir das cascas, entrecascas, fiapos e fibras (Vizolli, Santos, 2010, Viletti et. al. 2015).

Dessa a forma, a produção de mandioca tomou corpo e força na região do Caeté, o qual, hoje, toma como uma atividade titulada pelo aspecto cultural muito valorizado pelos agricultores. Por mais que os fatores de mercado, tecnologia, estruturais e sistêmicos venham modernizar a cadeia produtiva, pular etapas ou acelerar faz com que a farinha perca a qualidade (Vilpoux, 2008). Assim sendo, as etapas produtivas são as seguintes: deixar de molho e realizar a lavagem, ralação, prensagem, secagem, grolagem, escaldamento, peneiramento, esfarelamento, resfriamento, embalagem e armazenamento (Viletti et.al.2015). Esses procedimentos podem ser melhor visualizados na figura 1.

Figura 1: O processo de produção da farinha de mandioca

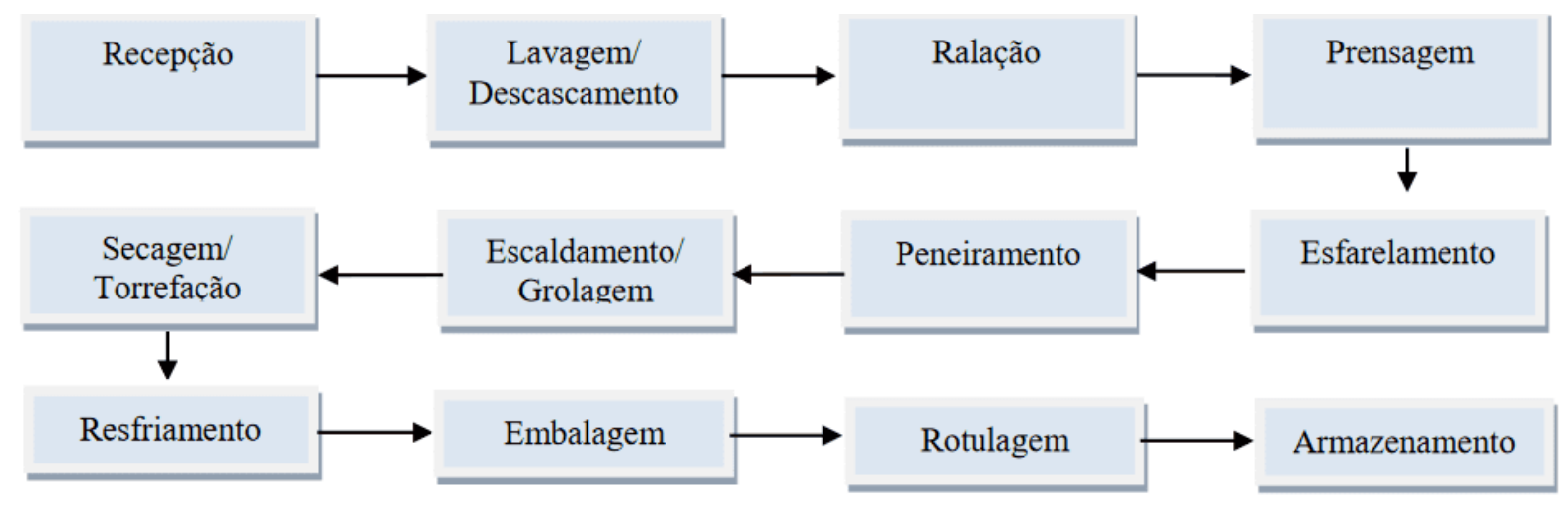

Fonte: Viletti et al. (2015).

A cultura da mandioca, associada à agricultura familiar, adequa-se as pretensões sociais do país por permitir o desenvolvimento humano bem como da unidade produtiva (Castro; Moreira, 2016). Em outro olhar, a fabricação da farinha demanda um apoio no quesito produtividade e qualidade como forma de manter a competitividade no mercado, adequando-se, para tanto, aos padrões econômicos de desenvolvimento necessários para sustentabilidade. Portanto, a produção agrícola da mandioca é geradora de oportunidade de negócio e renda (Castro; Moreira, 2016; Oliveira; Gorh, 2018). De fato, a obtenção de renda deve ser gerenciada como forma 
de manter a continuidade empresarial, gerando, assim, uma assimetria mais relevante que está associada ao conhecimento e avaliação de forma responsável nas empresas dos possíveis riscos.

\subsection{A CONTABILIDADE E A GESTÃO}

Os padrões contábeis estão interligados ao processo de gestão e a contabilidade por meio da aplicação de ferramentas de controle que não estão molduradas de acordo com os requisitos fiscais e trabalhistas brasileiros. Direcionam-se a partir de metodologias capazes de gerar informações precisas, e, ao mesmo tempo, atua como um instrumento eficaz, logo, recomendado para os processos de tomada de decisão (Hall et. al. 2012). Isso perfaz a necessidade de prever e reverter problemas que possam enfrentar, adotando, para isto, medidas preventivas. Dentre as diversas funções e ferramentas destinadas ao domínio contábil, optou-se, para esta pesquisa, a gestão de caixa e a gestão de risco operacional, visto que são procedimentos que se complementam na realização de diagnósticos.

\subsubsection{GESTÃO DE CAIXA}

A gestão do caixa está relacionada a ação de administração de recursos de liquidez que podem se apresentar tanto no formato de espécie como a partir de contas bancárias. São demonstrados por meio de caixa imediato e a longo prazo e se destacam devido à garantia do controle da estabilidade do negócio (Frezatti, 1997; Gitman, 2001; Hoji, 2003; Carlos Filho et. al. 2014; Silva Filho et. al. 2015). Vinculase, para tanto, à abordagem de caixa, e, dessa forma, todos os recursos disponíveis para as empresas são utilizados quando necessários e quando se detecta a presença de uma má gestão. Segundo Carlos Filho et al (2014) e Silva Filho et al (2015), os dados relacionados à gestão do caixa são importantes pois surgem em eventos diários dessas empresas, e, assim, torna-se necessário reportar, a partir de relatórios contábeis-financeiros, as melhores formas para que esses dados sejam considerados no processo de tomada de decisão. 
São necessários, ainda, para a realização de análises inerentes à capacidade da organização de solver para com as suas obrigações de forma imediata ou não. Assim sendo, essas informações são de interesse direto dos credores dessas empresas. Os pequenos empreendimentos, de forma geral, utilizam relatórios gerenciais para exercer controle e dar forma ao planejamento dos recursos de modo mais eficiente e eficaz. Destarte, como não possui ou qualifica seus recursos ou ativos e passivos, pequenas empresas tendem possuir recursos imediatos para atender aos eventos e transações rotineiras (MATIAS; LOPES JÚNIOR, 2002). Dessa forma, por meio da demonstração contábil, o fluxo de caixa assume uma função relevante no processo de planejamento financeiro e, assim, pode ser compreendido como o demonstrativo que deve viabilizar o controle e efetuar os registros direcionados à movimentação do caixa. Nesse sentido, consegue detalhar as entradas e saídas dos recursos financeiros realizados em um determinado período.

Segundo Friedrich e Brondani (2005) o fluxo de caixa deve demonstrar e representar uma prática dinâmica que deve constantemente atualizada, pois auxilia, diretamente, nos processos diários e diversos de tomada de decisão nas empresas. Para Oliveira, Ramalho e Moura (2013), reconhecer o fluxo de caixa de risco é importante para que as recomendações de Brigham e Gapenski (1994) em relação a melhores condições para se manter no mercado sejam atendidas. Já para Stickney e Weil (2001) e Marques et al (2008), a análise do ciclo de vida de uma empresa possibilita identificar a situação econômica na qual a entidade se encontra em um dado momento. Nesse sentido, todas as ações de gestão de caixa contemplam um plano orçamentário adotado pela gestão de caixa como um caminho para alcançar os diversos objetivos empresariais além de identificar o nível de lucro empresa por meio do sucesso dos ativos (Figueiredo; Caggiano, 2008; Padoveze, 2012).

\subsubsection{GESTÃO DE RISCOS}

Para tanto, o risco, de acordo com Carvalho, Trapp (2004) e Rodrigues (2008), vem de uma abordagem voltada à multiplicidade de campos de abrangência de objetivos que se apresenta por meio de uma situação que acerta possibilidades de perdas e não perdas relativas à transciência e a hermenêutica sobre as ações presentes na 
definição de bem ou direito. O risco tem uma conotação negativa, entretanto, quando empregado sob investimento pode remeter a resultados favoráveis, ou seja, a um retorno acima do esperado (Crouhy; Galai; Mark, 2004; Damoran, 2010).

A visão vem tem sido abordada, principalmente, em pesquisas no domínio das finanças (Jorion, 2003; Damodaran, 2010; Assaf Neto, 2009), e, dessa forma, tem-se utilizado a controladoria como instrumento identificador dos possíveis riscos que podem a vir a prejudicar a existência de uma organização (PADOVEZE, 2015). Nesse contexto, os negócios empresariais estão relacionados com a administração de risco (Brigham, Gapenski, 1994, Jorion,2003). Esses riscos se classificam em: de crédito, de liquidez, operacional e legal. Tal fenômeno pode ser observado na tabela 1.

Tabela 1: Classificação dos riscos

\begin{tabular}{|c|c|c|}
\hline Riscos & Abordagens & Autores \\
\hline Mercado & $\begin{array}{l}\text { Trata-se de quando valor de um } \\
\text { investimento modificam resultado de } \\
\text { forças de mercado. }\end{array}$ & $\begin{array}{l}\text { Altman, Caouette } \\
\text { Narayanan (2000) }\end{array}$ \\
\hline Crédito & $\begin{array}{l}\text { Relaciona-se as perdas ocasionadas } \\
\text { pela não honra de compromissos }\end{array}$ & $\begin{array}{l}\text { Duarte Jr. (1996); Goulart } \\
\text { (2004) }\end{array}$ \\
\hline Liquidez & $\begin{array}{l}\text { São ocasionados pelos problemas de } \\
\text { risco de insolvência empresarial }\end{array}$ & $\begin{array}{l}\text { Besssi (1998); Saunders } \\
\text { (2000), Assaf Neto, Silva } \\
\text { (2009) }\end{array}$ \\
\hline Operacional & $\begin{array}{l}\text { Está inerente à numerosas falhas de } \\
\text { execução dos procedimentos, } \\
\text { processos e do próprio negócio. }\end{array}$ & $\begin{array}{l}\text { Jorion (2003), Bis (2003), } \\
\text { Cruz (2003), Carvalho, } \\
\text { Trapp, Chan (2004) }\end{array}$ \\
\hline Legal & $\begin{array}{l}\text { Trata-se de um risco oriundo de } \\
\text { processos internos, sistemas externos } \\
\text { que se encontram inadequado. }\end{array}$ & Bis (2003), Zeno (2007) \\
\hline
\end{tabular}

Fonte: Elaborado pelos Autores (2018). 
A partir destas abordagens, os acontecimentos incertos ou perdas imputadas se caracterizam pelo risco no processo de estudo presente nas diversas situações, por exemplo, o ato de parar de respirar é um risco, se eu parar de respirar, logo, morro. De fato, os riscos se relacionam com as perdas financeiras decorrentes de ações gerenciadas de forma inadequada bem como de exposições indevidas. Isso faz com que a controladoria nas empresas não esteja imune a ação dos riscos, mas a partir deles devem manter ferramentas de trabalho capazes de manter um processo sustentável para as empresas de forma a evitar futuros incertos (Roehl- Anderson; Bragg, 2005; Padoveze, 2012, 2015). Outro ponto importante do risco é estudar cenários compostos por pessoas interessadas em otimizar os próprios ganhos e que podem estar vivenciando uma espécie de conflito.

Desta forma, diante deste cenário de crise e a luta da população por novas metodologias de investimento, faz com que esta seja de grande valia. Para Padoveze $(2012,2015)$ a gestão de risco deve ser monitorada por meio de uma arquitetura informacional que deve ser composta a partir de um estudo do ambiente externo e interno como forma de avaliar a conformidade das ações empregadas assim como a percepção do desempenho organizacional. Desse modo, Jorion (2003) e Duarte Jr. (2001) qualificam que o risco operacional vem mensurar as possíveis perdas nos sistemas informacionais. Esses não resistem a falhas humanas ou externalidades de mercado. Portanto, o escopo teórico é a defesa da necessidade de se colocar na posição do outro, e, a partir desse exercício, tentar prever o que se deve fazer em uma determinada situação. As interações devem ser modeladas a partir da consideração de benefícios e prejuízos de ambos, para, assim, chegar a uma melhor ação estratégica (CHAN; MARQUES, 2017).

\section{PROCEDIMENTOS METODOLÓGICOS}

Os micros empreendimentos econômicos foram escolhidos de forma intencional, uma vez que essas unidades produtivas são as únicas na região do Caeté e se localizam nas proximidades do município de Bragança, no Estado do Pará. Trabalham, culturalmente, com a produção de farinhas e estão produzindo, a quatro anos, as farinhas saborizadas, sendo este estudo pioneiro nestas organizações. Esses 
empreendimentos são compostos por três empresas de produção chamadas, pelos sócios, de colônias. Trata-se de um aglomerado de grupos compostos por 6 a 8 famílias que trabalham, entre seus participantes, em sociedade, compartilhando equipamentos e participando de todas as etapas do processo produtivo em conjunto. Para melhor analisar o processo de gestão das empresas, trabalhou-se com a separação destes arranjos atribuídos para análise da gestão de caixa e de riscos. Por questões de sigilo, foram adotadas as seguintes classificações para as empresas: A, $\mathrm{B}$ e C.

Os dados foram coletados a partir da aplicação de um questionário composto por 12 perguntas elaboradas pelas autoras. Ele foi desenvolvido para se qualificar as empresas estudadas e verificar como são feitos os procedimentos de gestão de caixa e de riscos. O questionário foi aplicado à 34 gestores. A pesquisa respeitou a Resolução no-466, de 12 de dezembro de 2012, que trata do respeito pela dignidade humana e pela especial proteção devida aos participantes das pesquisas científicas envolvendo seres humanos. As respostas obtidas foram classificadas com o auxílio da ferramenta Excel, da Microsoft, para a tabulação dos dados bem como para a mensuração, em percentuais, das informações concedidas pelos entrevistados. As questões, de forma geral, foram de múltipla escolha. Entretanto, algumas das colocações foram obtidas, também, de maneira informal, a partir de gravações. Essas conversas delinearam os desafios dessas organizações bem como sugeriram propostas de melhoria. 
Tabela 2: Questionário de pesquisa

\section{Dados da Empresa}

Qual o grau de instrução dos respondentes

Qual a área de estudo escolhida pelos respondentes que se encontram no ensino superior completo e incompleto?

\begin{tabular}{l|l|}
\multicolumn{1}{|c|}{ Gestão de Caixa } & \multicolumn{1}{c|}{ Gestão de Risco } \\
\hline $\begin{array}{l}\text { Qual o grau de importância das informações de } \\
\text { venda }\end{array}$ & $\begin{array}{l}\text { Qual o grau entendimento da importância de se } \\
\text { avaliar risco } \\
\text { Qual a utilidade das informações de produção na opinião, qual risco a organização está sujeita } \\
\text { atividade empresarial } \\
\begin{array}{l}\text { Entendimentos sobre a composição da der mais falhas? } \\
\text { disponibilidade de caixa }\end{array}\end{array}$ \\
$\begin{array}{l}\text { Qual a principal destinação das sobras de caixa } \\
\text { Com que frequência se faz o controle do caixa } \\
\text { Utiliza-se da gestão de caixa no processo decisório, } \\
\text { é realizado em que momento? }\end{array}$ & $\begin{array}{l}\text { Uecisão de } \\
\text { Realiza a verificação de falhas não intencionais no } \\
\text { processo produtivo }\end{array}$ \\
\hline
\end{tabular}

Fonte: Elaborado pelos Autores (2018).

No processo de análise também foi elaborada a demonstração do fluxo de caixa do período correspondente a seis meses do exercício do ano de 2016. Com essa observação, objetivou-se analisar, por meio da avaliação, a movimentação de caixas das empresas, para, posteriormente, apresentar um instrumento capaz de permitir a avaliação inerente à situação financeira para uma melhor tomada de decisão, conforme recomenda os estudos de Friedrich e Brondani (2005), Oliveira, Ramalho e Moura (2013) e Silva Filho et. al. (2015). Para a análise das tabelas adotou-se a apresentação individual dos respondentes, entretanto, ao inferir sobre as informações, optou-se por efetuar uma análise das três colônias, e, assim, destacou-se a representação da soma dos respondentes gestores pelo total de respondentes nas organizações. Com a observação dos dados criou-se tabelas que permitiram inferir sobre as repostas obtidas e confronta-las com o referencial teórico, permitindo-se, dessa forma, avaliar a gestão do caixa e dos riscos operacionais. 


\section{ANÁLISES E DISCUSSÕES}

\subsection{PERFIL DOS ENTREVISTADOS DAS EMPRESAS}

As organizações estudadas de produção de farinha são compostas por três colônias de produção. Na colônia $A$ há 8 sócios, na colônia $B$ há 16 sócios e na colônia $C$ há 10 sócios. Todos os sócios são familiares e participantes ativos da administração e do processo produtivo da farinha, não possuindo, então, empregados, assim são responsáveis pelas próprias vendas em feiras, nas comunidades, em restaurantes locais e em empresas parceiras da cidade de Belém. Segundo os dados da tabela 3, emprega-se os seguintes preços de venda.

Tabela 3: Preço de venda dos produtos fabricados.

\begin{tabular}{|l|l|l|l|}
\hline Produto & $A$ & $B$ & $C$ \\
\hline Farinha d'agua & $R \$ 6,00$ & $R \$ 6,00$ & $R \$ 6,00$ \\
\hline Farinha com jambu & $R \$ 9,00$ & $R \$ 10,00$ & $R \$ 9,00$ \\
\hline Farinha com jambu e charque & $R \$ 10,00$ & $R \$ 10,00$ & $R \$ 10,00$ \\
\hline Farinha com açaí & - & $R \$ 10,00$ & $R \$ 10,00$ \\
\hline Farinha com beterraba & - & $R \$ 9,00$ & - \\
\hline Farinha de camarão & $R \$ 11,00$ & $R \$ 12,00$ & $R \$ 10,00$ \\
\hline
\end{tabular}

Fonte: Elaborado pelos autores (2018).

A partir destas informações de preço do produto, indagou-se sobre o grau de instrução dos participantes dos micro empreendimentos bem como sobre a área de atuação profissional dos entrevistados que se encontram no ensino superior, uma vez que o desenvolvimento de competências é um elemento que evidencia e favorece o acesso ao mercado bem como o aumento da capacidade produtiva (Winckler; Molinari, 2011). Tal afirmação pode ser comprovada com a tabela quatro. 
Tabela 4: Grau de instrução versus área de formação

\begin{tabular}{|c|c|c|c|c|c|c|c|}
\hline \multicolumn{8}{|c|}{ Grau de instrução dos respondentes } \\
\hline \multirow[t]{2}{*}{ Itens } & \multicolumn{2}{|l|}{ A } & \multicolumn{3}{|c|}{ B } & \multicolumn{2}{|l|}{ C } \\
\hline & Freq & $\%$ & \multicolumn{2}{|c|}{ Freq } & $\%$ & \multirow[t]{2}{*}{ Freq } & \multirow[t]{2}{*}{$\%$} \\
\hline Ensino Fundamental & 1 & $13 \%$ & 2 & 13 & $\%$ & & \\
\hline $\begin{array}{l}\text { Ensino médio } \quad- \\
\text { incompleto }\end{array}$ & & & 6 & $3 \varepsilon$ & $\%$ & 1 & $10 \%$ \\
\hline Ensino médio - completo & 3 & $38 \%$ & & $0^{\circ}$ & & 3 & $30 \%$ \\
\hline $\begin{array}{l}\text { Ensino Superior- } \\
\text { Incompleto }\end{array}$ & 2 & $25 \%$ & 5 & 31 & $\%$ & 2 & $20 \%$ \\
\hline Ensino Superior Completo & 2 & $25 \%$ & 3 & 19 & $\%$ & 4 & $40 \%$ \\
\hline Total & 8 & $100 \%$ & 1 & 10 & $0 \%$ & 10 & $100 \%$ \\
\hline \multicolumn{8}{|c|}{$\begin{array}{l}\text { Área de estudo escolhida pelos respondentes que se encontram no ensino superior } \\
\text { completo e incompleto? }\end{array}$} \\
\hline \multirow[t]{2}{*}{ Itens } & \multicolumn{3}{|l|}{ A } & \multicolumn{2}{|l|}{ B } & \multicolumn{2}{|l|}{ C } \\
\hline & Freq & $\%$ & & Freq & $\%$ & Freq & $\%$ \\
\hline Pedagogia & 1 & & & 2 & $25 \%$ & 1 & $17 \%$ \\
\hline Biologia & - & - & & 1 & $13 \%$ & 2 & $33 \%$ \\
\hline Gestão Ambiental & 1 & 25 & & - & - & 1 & $17 \%$ \\
\hline Letras & - & - & & 1 & $13 \%$ & - & - \\
\hline História & 1 & 25 & & - & - & 1 & $17 \%$ \\
\hline Educação física & 1 & 25 & & 2 & $25 \%$ & - & - \\
\hline Administrador & - & & & 2 & $25 \%$ & 1 & $17 \%$ \\
\hline Total & 4 & & & 8 & $100 \%$ & 6 & $100 \%$ \\
\hline
\end{tabular}

Fonte: Elaboradora pelos Autores (2018)

Nota-se que poucos gestores da produção da farinha têm formação em áreas empresariais, no caso, no curso de administração. Dessa forma, ao analisar as três colônias, especialistas nesse curso representam $16 \%$ do total. A área que possui a maior quantidade de pessoas é o curso de pedagogia, com um total de $22 \%$. As 
demais áreas de estudo foram distribuídas de modo igual. Compreender o grau de formação e área de conhecimento torna-se importante quando se pretende avaliar a importância dada ao gerenciamento de caixa e a gestão dos riscos envolvidos no processo produtivo e, também, do modo como esses problemas são solucionados.

\section{GESTÃO DE CAIXA E GESTÃO DE RISCO NAS EMPRESAS DE ESTUDO}

\subsection{GESTÃO DE CAIXA}

Ao avaliar a gestão de caixa dos gestores e participantes das três empresas, foi possível registrar os aspectos relacionados à disponibilidade de caixa dos entrevistados. Nessa análise, elaborou-se, primeiramente, uma avaliação sobre a importância das informações relacionadas às vendas e produção, conforme os dados fornecidos pela tabela cinco.

Tabela 5: Informações de venda e produção

Grau de importância das informações de venda

\begin{tabular}{|c|c|c|c|c|c|c|}
\hline \multirow[t]{2}{*}{ Itens } & \multicolumn{2}{|l|}{ A } & \multicolumn{2}{|l|}{ B } & \multicolumn{2}{|l|}{ C } \\
\hline & Freq & $\%$ & Freq & $\%$ & Freq & $\%$ \\
\hline Pouco importante & 1 & $13 \%$ & 2 & $13 \%$ & 1 & $10 \%$ \\
\hline Importante & 1 & $13 \%$ & 6 & $38 \%$ & 3 & $30 \%$ \\
\hline Muito importante & 6 & $75 \%$ & 8 & $50 \%$ & 6 & $60 \%$ \\
\hline Total & 8 & $100 \%$ & 16 & $100 \%$ & 10 & $100 \%$ \\
\hline \multicolumn{7}{|c|}{ Utilização das informações de produção na atividade empresarial } \\
\hline \multirow[t]{2}{*}{ Itens } & \multicolumn{2}{|l|}{ A } & \multicolumn{2}{|l|}{ B } & \multicolumn{2}{|l|}{ C } \\
\hline & Freq & $\%$ & Freq & $\%$ & Freq & $\%$ \\
\hline Para formação do preço de venda & 7 & $88 \%$ & 10 & $63 \%$ & 3 & $30 \%$ \\
\hline 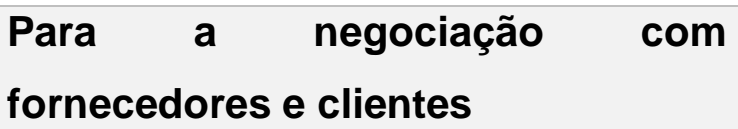 & 1 & $13 \%$ & 6 & $38 \%$ & 7 & $70 \%$ \\
\hline Total & 8 & $100 \%$ & 16 & $100 \%$ & 10 & $100 \%$ \\
\hline
\end{tabular}


Fonte: Elaborados pelos autores (2018)

As informações obtidas remetem à formação do caixa e ao entendimento sobre elementos que os gestores privilegiam diante à formação de receita e o consequente caixa. Nota-se que todas as organizações possuem $58 \%$ dos respondentes, e, assim, consideram como muito importante a avaliação de venda como forma de compor o caixa da organização e efetuar o pagamento não somente das famílias, mas das dívidas adquiridas na produção, principalmente na compra de carvão, uma vez que não se utiliza madeira local, pois a comunidade se encontra dentro da área da Reserva Extrativista Marinha Tracuateua (RESEX). Ao se analisar o conhecimento sobre a disponibilidade de caixa e sobre as prioridades de destinação de recursos de caixa nas organizações estudadas temos os seguintes dados:

Tabela 6: Conhecimento de disponibilidades versus destinação de caixa

Entendimentos sobre a composição da disponibilidade de caixa

\begin{tabular}{|c|c|c|c|c|c|c|}
\hline \multirow[t]{2}{*}{ Itens } & \multicolumn{2}{|l|}{ A } & \multicolumn{2}{|l|}{ B } & \multicolumn{2}{|l|}{$\mathbf{C}$} \\
\hline & Freq & $\%$ & Freq & $\%$ & Freq & $\%$ \\
\hline Caixa e bancos & 1 & $13 \%$ & 8 & $50 \%$ & 3 & $30 \%$ \\
\hline $\begin{array}{l}\text { Caixa, bancos, aplicações } \\
\text { financeiras }\end{array}$ & 3 & $38 \%$ & 3 & $19 \%$ & 2 & $20 \%$ \\
\hline $\begin{array}{l}\text { Caixa, bancos, aplicações } \\
\text { financeiras e imobilizado }\end{array}$ & 2 & $25 \%$ & 1 & $6 \%$ & 2 & $20 \%$ \\
\hline $\begin{array}{l}\text { Caixa, banco aplicações financeiras } \\
\text { e valores a receber }\end{array}$ & 2 & $25 \%$ & 4 & $25 \%$ & 3 & $30 \%$ \\
\hline Total & 8 & $100 \%$ & 16 & $100 \%$ & 10 & $100 \%$ \\
\hline \multicolumn{7}{|l|}{ Destinação das sobras de caixa } \\
\hline \multirow[t]{2}{*}{ Itens } & \multicolumn{2}{|l|}{ A } & \multicolumn{2}{|l|}{ B } & \multicolumn{2}{|l|}{ C } \\
\hline & Freq & $\%$ & Freq & $\%$ & Freq & $\%$ \\
\hline Pagamento das dividas & 3 & $38 \%$ & 8 & $50 \%$ & 5 & $50 \%$ \\
\hline Pagamento dos sócios & 5 & $63 \%$ & 8 & $50 \%$ & 4 & $40 \%$ \\
\hline Manter no caixa & - & & - & & 1 & $10 \%$ \\
\hline
\end{tabular}


Fonte: Elaborada pelos Autores (2018)

Nota-se que, na avaliação de disponibilidade de caixa, a maior parte dos gestores das três organizações $26 \%$ possui formação voltada à disponibilidade de caixa composta por caixa, banco, aplicações financeiras e por valores a receber. Ressalta-se que esta visão não está adequada, de acordo com diversos autores (Carlos Filho et. al. 2014, Silva Filho et. al. 2015). Eles ressaltam que alguns elementos devem ser considerados, como a disponibilidade dos valores em caixa, os depósitos bancários à vista assim como todos os numerários que venham a estar em trânsito e, também, as aplicações de liquidez imediata. Infere-se que $23 \%$ do total dos gestores das três empresas tem a compreensão em conformidade com os autores. Sobre a destinação de recursos do caixa, $50 \%$ são destinados para pagamentos dos sócios, assim, este depende, exclusivamente, da atividade econômica e precisa estar presente, de forma constante, no processo produtivo. Estas destinações de caixas são realizadas, no mínimo, semanalmente.

Na sequência, realiza-se o pagamento das dívidas e, por fim, mantem-se recursos em caixa. Observa-se que somente a coluna $C$ possui reserva de recursos em caixa, sendo uma das empresas um sócio administrador. O registro de caixa executado pelas empresas é feito por meio do uso de cadernos. Os gestores efetuam o registro de todas as vendas e pagamentos realizados diariamente. Após este registro, os gestores computam esta informação em um livro movimento de caixa e em uma planilha do Excel, como forma de fazer o acompanhamento. Este acompanhamento é feito a partir de um fluxo de caixa no qual são classificadas as entradas de todas as movimentações em dinheiro e recebimentos dos clientes. Para as saídas são consideradas todas as contas a pagar. Todos os processos de emissão de notas fiscais de saídas são realizados em blocos de notas fiscais e entregues ao contador mensalmente. Dessa forma, pretende-se entender como o controle de caixa e gestão são executados. 
Tabela 7: Controle de caixa versus gestão de caixa

Com que frequência se faz o controle do caixa

\begin{tabular}{|c|c|c|c|c|c|c|}
\hline \multirow[t]{2}{*}{ Itens } & \multicolumn{2}{|l|}{ A } & \multicolumn{2}{|l|}{ B } & \multicolumn{2}{|l|}{ C } \\
\hline & Freq & $\%$ & Freq & $\%$ & Freq & $\%$ \\
\hline Diariamente & 6 & $75 \%$ & 14 & $88 \%$ & 8 & $80 \%$ \\
\hline Semanalmente & 2 & $25 \%$ & 2 & $13 \%$ & 2 & $20 \%$ \\
\hline Total & 8 & $100 \%$ & 16 & $100 \%$ & 10 & $100 \%$ \\
\hline \multicolumn{7}{|c|}{ Utiliza-se da gestão de caixa no processo decisório, é realizado em que momento? } \\
\hline \multirow[t]{2}{*}{ Itens } & \multicolumn{2}{|l|}{ A } & \multicolumn{2}{|l|}{ B } & \multicolumn{2}{|l|}{ C } \\
\hline & Freq & $\%$ & Freq & $\%$ & Freq & $\%$ \\
\hline Controle organizacional & 5 & $63 \%$ & 8 & $50 \%$ & 5 & $50 \%$ \\
\hline Analise de desempenho & 2 & $25 \%$ & 4 & $25 \%$ & 3 & $30 \%$ \\
\hline Obter vantagens competitiva & 1 & $13 \%$ & 4 & $25 \%$ & 2 & $20 \%$ \\
\hline Total & 8 & $100 \%$ & 16 & $100 \%$ & 10 & $100 \%$ \\
\hline
\end{tabular}

Fonte: Elaborado pelos autores (2018)

Diante da análise sobre a utilização da gestão de caixa nas empresas estudadas, verificou-se, primeiramente, a frequência na qual a disponibilidade de caixa é administrada. Detectou-se que $82 \%$ das empresas verificam o fluxo de caixa diariamente. Percebeu-se, também, que nenhuma empresa estudada administra esses caixas em períodos superiores a uma semana. Para avaliação da gestão do caixa as empresas buscam executar seu controle organizacional por meio de planilhas como forma de acompanhar a movimentação financeira que representa $52 \%$; a análise de desempenho representa $26 \%$ e a obtenção de vantagens competitivas representa $22 \%$. Esses valores foram obtidos ao referenciar o total das três empresas.

De fato, todas as empresas planejam suas atividades e tentam programar os recebimentos e pagamentos efetuando o acompanhamento de $100 \%$ do planejado como recebível ou pagável. Assim, para avaliar a evolução da gestão de caixa das três empresas por meio do desenvolvimento do fluxo de caixa das três empresas optaram por avaliar os saldos de caixa. 
Tabela 7: Demonstração de fluxo de caixa das empresas

DEMONSTRAÇÃO DE FLUXO DE CAIXA - Método Direto

\begin{tabular}{|c|c|c|c|}
\hline ATIVIDADES OPERACIONAIS & A & B & C \\
\hline Recebimentos de Clientes (DR) & $12.320,00$ & $6.232,00$ & $19.960,00$ \\
\hline Recebimento de Vendas à Vista & $39.560,20$ & $78.960,20$ & $48.562,30$ \\
\hline Pagamento de Compras à Vista & $18.230,00$ & $38.652,30$ & 25.321,00 \\
\hline Pagamentos a Fornecedores & $-9.650,00$ & $\begin{array}{l}- \\
19.254,00\end{array}$ & $20.358,00$ \\
\hline Pagamento de Despesas com Vendas & $\begin{array}{l}- \\
12.532,00\end{array}$ & $21.560,00$ & $\begin{array}{l}- \\
19.652,30\end{array}$ \\
\hline Pagamento de Despesas Administrativas & $-240,00$ & $-2.150,00$ & $-1.520,00$ \\
\hline $\begin{array}{l}\text { Decréscimo de Caixa originado das atividades } \\
\text { operacionais }\end{array}$ & $11.228,20$ & $3.575,90$ & $1.671,00$ \\
\hline ATIVIDADES DE FINANCIAMENTO & - & - & - \\
\hline $\begin{array}{l}\text { Acréscimo de Caixa originado das Atividades } \\
\text { de Financiamentos }\end{array}$ & - & - & - \\
\hline ATIVIDADES DE INVESTIMENTOS & - & - & - \\
\hline Recebimento de Venda de Imobilizado & - & $2.540,00$ & - \\
\hline Pagamento de Aquisição de Imobilizado & - & $-5.260,00$ & $-1.320,00$ \\
\hline $\begin{array}{l}\text { Decréscimo de Caixa originado das Atividades } \\
\text { de Investimentos }\end{array}$ & - & $-2.720,00$ & $-1.320,00$ \\
\hline ACRÉSCIMO DE CAIXA DO PERÍODO & $11.228,20$ & 855,90 & 351,00 \\
\hline $\begin{array}{l}\text { Saldo de Caixa, Bancos e Aplicação. } \\
\text { Financeira. Liquidez Imediata 31/06/2016 }\end{array}$ & $1.324,12$ & $1.985,23$ & $1.128,59$ \\
\hline Saldo de Caixa e Bancos em 31/07/2016 & $3.240,00$ & $4.622,15$ & $4.530,28$ \\
\hline Variação de Caixa & $1.915,88$ & $2.636,92$ & $3.401,69$ \\
\hline
\end{tabular}

Fonte: Elaborado pelo Autores (2018) 
Nota-se que, ao avaliar os saldos de caixa, a empresa $\mathrm{C}$ é a que possui maiores saldos de caixa em relação às demais e que, na avaliação de controle de caixa, possui uma gestão administradora que tem uma postura mais forte para formação de caixa. Além disso, na sequência de avaliação de gestão de saldos de caixa temos a empresa B e A. Observa-se que ambas podem aplicar seus saldos de caixa para compor reserva financeira para conseguir ser competitiva na entre safra do produto, entretanto, $100 \%$ das organizações redistribuem os recursos e compram os primeiros insumos necessários para produção da farinha d'agua que é a base para adição de sabores. De acordo com os estudos de Friedrich e Brondani (2005), as empresas que apresentam fluxo de caixa têm a possibilidade de tomar a melhor decisão sobre suas atividades produtivas e consequente caixa. Entretanto, a formação de saldos de caixa não garante que a empresa não está sujeita a correr riscos os quais devem ser gerenciados para evitar perdas irreparáveis.

\subsection{GESTÃO DE RISCOS}

O gerenciamento de risco embasa as melhorias no processo de produção, como, também, no gerenciamento de caixa, uma vez que permite que a organização evolua em comum acordo com suas atividades. Nesta questão, indagou-se, aos entrevistados, sobre a relevância de avaliar os riscos e se os mesmos reconhecem que a organização pode estar sujeita a falhas internas e externas.

Tabela 8: relevância do risco versus proposição a falhas

Grau de entendimento da importância de se avaliar o risco

\begin{tabular}{|l|l|l|l|l|l|l|l|}
\hline & A & \multicolumn{3}{|l|}{ B } & \multicolumn{3}{l|}{ C } \\
\hline Itens & Freq & $\%$ & Freq & $\%$ & Freq & $\%$ \\
\hline Pouco importante & 1 & $13 \%$ & 2 & $13 \%$ & 1 & $10 \%$ \\
\hline Importante & 1 & $13 \%$ & 6 & $38 \%$ & 3 & $30 \%$ \\
\hline Muito importante & 6 & $75 \%$ & 8 & $50 \%$ & 6 & $60 \%$ \\
\hline Total & 8 & $100 \%$ & 16 & $100 \%$ & 10 & $100 \%$ \\
\hline
\end{tabular}

Na sua opinião, qual risco a organização está sujeita a ter mais falhas? 


\begin{tabular}{|l|l|l|l|l|l|l|}
\hline & A & \multicolumn{3}{l|}{ B } & \multicolumn{3}{l|}{ C } \\
\hline Itens & Freq & $\%$ & Freq & $\%$ & Freq & $\%$ \\
\hline $\begin{array}{l}\text { Riscos por falhas nos processos de } \\
\text { produção }\end{array}$ & 2 & $25 \%$ & 2 & $13 \%$ & 3 & $30 \%$ \\
\hline Riscos gerenciamento & & & & & & \\
\hline Riscos por eventos externos & 3 & $38 \%$ & 8 & $50 \%$ & 4 & $40 \%$ \\
\hline Riscos por pessoas e sistemas & 2 & $25 \%$ & 4 & $25 \%$ & 2 & $20 \%$ \\
\hline Total & 1 & $13 \%$ & 2 & $13 \%$ & 1 & $10 \%$ \\
\hline
\end{tabular}

Fonte: Elaborado pelas Autores (2018)

$\mathrm{Na}$ abordagem sobre a importância da avaliação dos riscos, a maioria dos respondentes informaram que dão muita importância a esta avaliação reconhecendo que tomam precauções para evitar situações de riscos nas suas operações. Informaram, ainda, que, no processo de falhas, os gestores acreditam que a maior parte de suas falhas podem ocorrer diante da gestão de caixa ou do cumprimento de obrigações com o fisco. Afirmam que não são detentores de total conhecimento, e, assim, acabam contratando contadores para auxilia-los. Além do mais, quanto aos riscos do processo de produção, os gestores reiteram que já ocorreram duas situações: a primeira foi o fato de pularem etapas de produção caseira da farinha, especificamente a parte de lavagem, comprometendo, assim, o sabor e a qualidade da farinha, os quais os fizeram perder o lote inteiro da produção.

O segundo momento atribuído pela não venda da produção por completo exigiu a procura por ações e soluções imediatas para garantir o sustento das famílias locais. Neste caso, houve ajuda da prefeitura municipal, pois adquiriu os lotes da produção e os incluiu na alimentação interna. Nota-se que a empresa está sujeita a muitos riscos ocasionados pela falta de um sistema de controle de estoque, de mercadoria e, também, de produção, mas isto, em nenhum momento, compromete o crescimento $\mathrm{e}$ retarda-o pelo tempo. Entretanto, avalia-se a falta de um sistema de informação adequado. Isso pode vir a comprometer a tomada de decisão (Padoveze, 2015). 
Tabela 9: Risco operacional na tomada de decisão

\begin{tabular}{|c|c|c|c|c|c|c|}
\hline \multicolumn{7}{|c|}{ Utiliza a gestão de risco operacional no processo de decisão } \\
\hline \multirow[t]{2}{*}{ Itens } & \multicolumn{2}{|l|}{ A } & \multicolumn{2}{|l|}{ B } & \multicolumn{2}{|l|}{ C } \\
\hline & Freq & $\%$ & Freq & $\%$ & Freq & $\%$ \\
\hline Sim & 7 & $88 \%$ & 14 & $88 \%$ & 9 & $90 \%$ \\
\hline Não & 1 & $13 \%$ & 2 & $13 \%$ & 1 & $10 \%$ \\
\hline Total & 8 & $100 \%$ & 16 & $100 \%$ & 10 & $100 \%$ \\
\hline \multicolumn{7}{|c|}{ Realiza a verificação de falhas não intencionais no processo produtivo } \\
\hline \multirow[t]{2}{*}{ Itens } & \multicolumn{2}{|c|}{ A } & \multicolumn{2}{|c|}{ B } & \multicolumn{2}{|l|}{ C } \\
\hline & Freq & $\%$ & Freq & $\%$ & Freq & $\%$ \\
\hline Sim & 5 & $63 \%$ & 14 & $88 \%$ & 8 & $80 \%$ \\
\hline Não & 3 & $38 \%$ & 2 & $13 \%$ & 2 & $20 \%$ \\
\hline Total & 8 & $100 \%$ & 16 & $100 \%$ & 10 & $100 \%$ \\
\hline
\end{tabular}

Fonte: Elaborado pelos autores (2018)

Ao avaliar a tomada de decisão envolvendo a gestão de risco, nota-se que os gestores entrevistados se utilizam de métodos de prevenção e controle, que, de fato, refletem na minimização de alguns dos principais riscos operacionais bem como de riscos internos que envolvem operações na etapa produtiva e riscos associados a eventos externos. De fato, existem lacunas na Gestão de Risco que precisam ser monitoradas e que podem ser solucionadas ao longo do tempo com o amadurecimento da organização (Padoveze, 2012, 2015; Santos Filho et. al. 2017).

\section{CONCLUSÃO}

O presente estudo teve como objetivo analisar como é executada a gestão de caixa e de riscos no processo de produção da farinha saborizada no município de Bragança, Região do Caeté. Os responsáveis conhecem, atribuem importância e utilizam as informações para a tomada de decisão decorrentes da Gestão de Caixa e de Gestão de Risco. A análise do estudo permite revelar que os gestores têm conhecimento acerca das disponibilidades de caixa e de risco, porém não possuem uma formação 
que permite que gerenciem sua organização de forma a manter saldos de caixas para serem reinvestidos nas empresas, o que prejudica o planejamento e o controle de seus recursos financeiros.Sobre a gestão de caixa, pode-se concluir que os gestores não possuem um bom conhecimento sobre disponibilidades de caixa, o que prejudica a gestão do mesmo no processo de geração de informações importantes para a tomada de decisões que são importantes para seus negócios.

Observou-se, também, que os gestores executam um fluxo de caixa apenas à curto prazo. Ao relacionar o planejamento dos seus fluxos de caixa os recebimentos e pagamentos, identificou-se um acompanhamento do caixa em curtos período, o que não elimina risco, mas o reduz ao comparar a sua falta. Sobre a gestão de risco, conclui-se que as empresas reconhecem o risco inerente as atividades produtivas, mais do que problemas que envolvam as situações de registro e de guarda de recursos financeiros, contribuindo, assim, para que a empresa crie lacunas que são vão ser solucionadas com o amadurecimento da organização assim como a informatização, para que os mesmos consigam monitorar. Portanto, muitas destas organizações devem desenvolver ações para gerenciar os riscos envoltos do caixa quando se sentirem necessidade de ampliar seus mercados. Isso exige mudanças de comportamento e de gestão.

De fato, a importância e a incipiência da gestão de caixa e de risco está direcionada a falta de padronização e de procedimentos e controles a serem empregados em prol da execução das atividades e da organização do caixa. A possibilidade de promover melhorias as etapas produtivas vêm com o propósito de eliminar os riscos identificados. Sugere-se, para pesquisas futuras, que essas sejam realizadas como forma de contribuir e difundir o conhecimento sobre a inovação da produção da farinha ao efetuar a saborização ao produto. Assim como a realização de outras pesquisas nestes empreendimentos, foi possível analisar outras variáveis como a gestão de custos e formação de preços. 


\section{REFERENCIAS}

Altaman, E. I.; Caouette, J. B.; Narayanan, P. Gestão do risco de crédito: o próximo grande desafio financeiro. Rio de Janeiro: Qualitymark, 2000.

Alves, R. N. B.; Modesto, M. S. Mercado exige características distintas de produção de farinha de tapioca em duas regiões no estado do Pará. 2013. Disponível em: http://www.ecodebate.com.br/2013/10/17/mercado-exigecaracteristicas-distintas-de-producao-de-farinha-de-tapioca-em-duas-regioes-noestado-do-para-por-raimundo-nonato-brabo-alves-e-moises-de-souza-modestojunior/. Acesso em: 06. Out. 2019.

Assaf Neto, A.; SILVA, C. A. T. Administração do capital de giro. 3 ed. São Paulo: Atlas, 2009.

Batalha, M. O; Silva, A. L. Gerenciamento de sistemas agroindustriais: definições, especificações, especificidades e correntes metodológicas. In: BATALHA, M. O. (Coord.). Gestão agroindustrial. 3. ed. São Paulo: Editora Atlas, 2009.

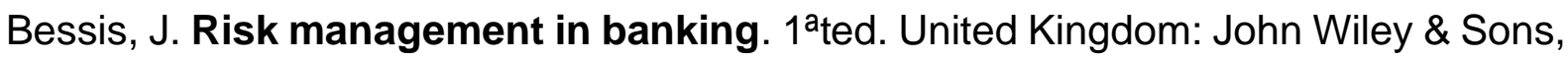
1998.

Bezerra, V. S. Farinhas de mandioca seca e mista Brasília, DF: Embrapa Informação Tecnológica. $2006 . \quad$ Disponível em: http://www.infoteca.cnptia.embrapa.br/infoteca/bitstream/doc/120197/1/00079010.pdf . Acesso em: 06. Out. 2019.

Bis (2003). Bank for International Settlements - Basel Committee on Banking Supervision. Sound practices for the management and supervision of $\begin{array}{llll}\text { operational } & \text { risk. } & 2003 . & \text { Disponível }\end{array}$ http://www.bis.org/publ/bcbs96.pdf?noframes=1. Acesso em: 06. Out. 2019.

Bragança, M. L. Processamento artesanal da fabricação da farinha de mandioca. Emater-MG. $2000 . \quad$ Disponível em: 
http://emater.mg.gov.br/doc\%5Csite\%5Cserevicoseprodutos\%5Clivraria\%5Agroind\% C3\%BAstria\%5CProcessamento\%20artesanal\%20da\%20fabrica\%3\%A7\%C3\%A3o \%20da\%20farinha\%20de\%20mandioca.pdf. Acesso em: 06. Out. 2019.

BRASIL. Empresa Brasileira de Pesquisa Agropecuária (EMBRAPA) Armazenamento da farinha de mandioca. Acre. 2009. Disponível em: http://hotsites.sct.embrapa.br/prosarural/programacao/2009/armazenamento-dafarinha-de-mandioca. Acesso em: 06. Out. 2019.

Brasil. Instrução Normativa Mapa 25/2011, de 8 de novembro de 2011. Estabelecer o Regulamento Técnico da Farinha de Mandioca. Diário Oficial [da] República Federativa do Brasil, Brasília, DF, 8 novembros. 2011. Disponível em: http://www.cidasc.sc.gov.br/classificacao/files/2012/08/INM00000052.pdf. Acesso em: 06. Out. 2019.

Brigham, E. F.; Gapenski, L. C. Financial Management: Theory and Practice. Florida: The Dryden Press, 1994.

Cardoso, C. E. L.; Souza, J. S. Aspectos econômicos. Cruz das Almas: Embrapa Mandioca e Fruticultura. (Embrapa Mandioca e Fruticultura. Circular Técnica, 37). 2000.

Carvalho, L. N.; Trapp, A. C. G.; Chan, B. L. Disclosure e risco operacional: uma abordagem comparativa em instituições financeiras que atuam no Brasil, na Europa e nos Estados Unidos. Revista de Administração da USP, v. 39, 2004.

Castro, J. E. G. de; Moreira, C. A. L. ASPECTOS ECONÔMICOS E SOCIAIS DA CADEIA PRODUTIVA DA MANDIOCA NO BRASIL. Revista Cientifica FACPED. Faculdade Padre Dourado, v.2, n.2, 2016.

Catelli, Armando. (Coord.) (2001). Controladoria - Uma abordagem da Gestão Econômica - GECON. 2. ed. São Paulo: Atlas. 
Chan, B. L.; Marques, F. T. Impactos do modelo regulatório de capital para risco de mercado: aplicação em uma sociedade de capitalização, uma seguradora e uma entidade aberta de previdência complementar. Revista Contabilidade \& Finanças, v. 28, n. 75 , p. $465-477,2017$.

Chisté, R. C. Estudo do processo de fabricação da farinha de mandioca. Belém, PA : Embrapa Amazônia Oriental. Disponível em: https://www.embrapa.br/amazoniaoriental/busca-de-publicacoes/-/publicacao/903120/estudo-do-processo-defabricacao-da-farinha-de-mandioca. Acesso em: 06. Out. 2019.

Crouhy, M.; Galai, D.; Mark, R. Gerenciamento de Risco: Abordagem Conceitual e Prática: Uma Visão Integrada dos Riscos de Crédito, Operacional e de Mercado. Rio de Janeiro: Qualitymark, São Paulo: SERASA, 2004.

Cruz, M. Modelagem quantitativa de risco operacional. In: DUARTE Jr., A. M.; VARGA, G. (Org.). Gestão de riscos no Brasil. Rio de Janeiro: Financial Consultoria, 2003.

Damodaran, A. Introdução à avaliação de investimentos: ferramentas e técnicas para a determinação do valor de qualquer ativo. 2. ed. Rio de Janeiro: Qualitymark, 2010.

Davenport, T. H. Ecologia da Informação: como as organizações gerenciam o sucesso na era da informação. 5. ed. São Paulo: Futura, 2002.

Dias, R. L. de C. J. A contabilidade como fonte de informação às micro e pequenas empresas do setor de serviços: um estudo no bairro da Barra da Tijuca na cidade do Rio de Janeiro no período de 2009 a 2010.2010. 142 f. Dissertação (Mestrado em Administração e Desenvolvimento Empresarial) Universidade Estácio de Sá, Rio de Janeiro, 2010.

Dias; J. C. R., Vasconcellos; J. T de C. As características qualitativas da informação contábil no desenvolvimento do controle social: uma análise da percepção dos conselheiros municipais do Recife sobre a utilidade das 
informações contábeis. 2011. Dissertação (Mestrado) - Programa de PósGraduação em Ciências Contábeis, Universidade Federal de Pernambuco, Recife, 2011.

Duarte Jr., A. M. Riscos: definições, tipos, medição e recomendações para seu gerenciamento - gestão de risco e derivativos. São Paulo: Atlas, 2001.

Duarte JR., A. M. Risco: definições, tipos, medição e recomendações para seu gerenciamento. Resenha BM\&F, São Paulo, v. 114, p. 25-33, 2003.

Fernandes, E. R. et al. O Uso do Sistema de Informação Contábil como Ferramenta para a Tomada de Decisão nas Empresas da Região de Contagem - Minas Gerais. In: IX Simpósio de excelência em gestão, 2012.

Fietz, E. Z.; Costa, A.; Beuren, I. M. Participação da Controladoria no processo de gestão das organizações: uma análise comparativa entre grandes indústrias de Santa Catarina do Rio Grande do Sul. Revista de Negócios, v. 12, n. 1, p. 29-41, 2007.

Figueiredo, S., Caggiano, P. C. Controladoria: teoria e prática. $4^{a}$ ed. São Paulo: Atlas, 2008.

Frezatti, F. Gestão do Fluxo de Caixa Diário. São Paulo: Atlas, 1997.

Friedrich, J.; Brondani, G. Fluxo de Caixa: sua importância e aplicação nas empresas. Revista Eletrônica de Contabilidade-UFSM/RS, Cascavel, v. 2, n. 2, p. 1-21. jun/nov, 2005.

Gitman, L. J. Princípios de Administração Financeira. São Paulo: Ed. Harbra, 2001.

Hall, R. J. et al. Contabilidade como uma ferramenta da gestão: um estudo em micro e pequenas empresas do ramo de comércio de Dourados-MS. Revista da Micro e Pequena Empresa, Campo Limpo Paulista, v. 6, n. 3, p. 4-17, 2012. 
Hoji, M. Administração Financeira: uma abordagem prática: matemática financeira aplicada, estratégias financeiras, análise, planejamento e controle financeiro. São Paulo: Atlas, 2003.

BRASIL. Instituto Brasileiro de Geografia e Estatística (IBGE). 2014. Levantamento sistemático da produção agrícola. Disponível em: hftp://ftp.ibge.gov.br/Producao_Agricola/Levantamento_Sistematico_da_Producao_A gricola_\%5Bmensal\%5D/Fasciculo/Ispa_201503.pdf. Acesso em; 06. Out. 2019.

Jorion, P. Value at risk: a nova fonte de referências para gestão de risco financeiro. 2. ed. São Paulo: Bolsa de Mercadorias \& Futuros (BM\&F), 2003.

Kingsley, S. et al. Operational Risk and Financial Institutions: Getting Started. In: Operational Risk and financial Institutions. London: Risk Books, 1998.

Kukalis, S. Agglomeration Economies and Firm Performance: The Case of Industry Clusters. Journal of Management, v. 36, n. 2, p. 453-481, 2010.

Marion, J. C. Contabilidade empresarial. São Paulo: Atlas, 2003.

Matias, A. B.; Lopes Junior, F. Administração financeira nas empresas de pequeno porte. São Paulo: Manole, 2002.

Nascimento, C. B. L. do. A problemática da informação imperfeita nas relações de consumo e a necessidade de proteção do vulnerável. RJLB, Ano 1 (2015), no 2, 2015.

Nassar, N. M. A. Mandioca: opção contra a fome. Estudos e lições no Brasil e no mundo. Revista Ciência Hoje, v. 39. n. 231, p. 30-39, 2006.

Oliveira, A. M. B.; Ramalho, R. O.; Moura, A. A. F.Gestão de Capital de Giro Líquido e de Fluxo de Caixa em Risco de Empresas de Bens Industriais Listadas na BM\&FBovespa. Revista de Contabilidade da UFBA, v. 7, n. 2, 2013. 
Oliveira, I. S. V. de; Gorh, C. F. Interação de Recursos em Redes Um Estudo em um Arranjo Produtivo Local de Calçados. Desenvolvimento em questão: Editora Unijuí, Ano 16, n. 43, p. 513-547, 2018.

Padoveze, C. L. Contabilidade Gerencial. 1ํed. Curitiba, PR: IESDE: Brasil, 2012.

Padoveze, C. L. Controladoria Estratégica e Operacional. $3^{\underline{a}}$ ed. rev. e atual. São Paulo: Cengage Learning, 2015.

Porter, M. The five Competitive Forces that shape Strategy. 2008.

Ribeiro, A; Freire, E. J.; Barella, L. A. A informação contábil como instrumento de apoio às micro e pequenas empresas: percepção dos gestores de micro e pequenas empresas de Paranaíta-MT, quanto à utilização de informações da contabilidade no processo de tomada de decisão, 2012.

Rodrigues, J. A. Gestão de risco atuarial. São Paulo: Saraiva, 2008.

Rodrigues; J. M.; Elias, W. G.; CAMPOS, E. S. Relevância da Informação Contábil: uma análise dos efeitos da contabilização dos gastos com pesquisa e desenvolvimento com a aplicação da Lei ํㅜ 11.638/2007 no mercado brasileiro. In: XIV Congresso USP. Controladoria e Contabilidade, 2014.

Roehl-Anderson, J. M.; Bragg, S. M. The controller's function. 3ª ed. New Jersey: Wiley, 2005.

Saunders, A. Administração de instituições financeiras. 2. ed. São Paulo: Atlas, 2000.

Silva Filho, L. L. da. et al. Gestão de custos e formação de preço de venda, gestão de caixa e gestão de riscos: um estudo exploratório no arranjo produtivo local gesseiro do estado de Pernambuco. Associação Brasileira de Custos, v. 10, n. 3, p. 107-142, 2015. 
Stickney, C. P.; Weil, R. L. Contabilidade Financeira: uma introdução aos conceitos, métodos e usos. São Paulo: Atlas, 2001.

Vieira, J. de. C. Desafios e perspectivas dos APLS de segunda geração. Mercator, v. 16, e16005, 2017.

Viletti; R; Junkes, V. H.; Groff, A. M. Processo de produção da farinha de mandioca seca. In: IX EEPA. Encontro de engenharia de Produção agroindustrial, 2015

Vilpoux, O. F. Competitividade da mandioca no Brasil, como matéria-prima para amido. Informações Econômicas, v. 38, n. 11, p. 27-38, 2008.

Vizolli, I.; Santos, R. M. G. Produção de farinha da mandioca: um estudo na comunidade quilombola lagoa da pedra. 2010. Disponível em: http://www.lematec.net/CDS/ENEM10/artigos/CC/T22_CC452.pdf. Acesso em: 06. Out. 2019.

Winckler, N. C.; Molinari, G. T. Competição, Colaboração, Cooperação e Coopetição: Revendo os Conceitos em Estratégias Interorganizacionais. Revista ADMpg Gestão Estratégica, v. 4, n. 1, 2011.

Zeno, J. M. C. Risco legal: uma introdução ao seu gerenciamento no atual cenário corporativo. 2007. 76 p. Dissertação (Mestrado) - Faculdade de Economia e Finanças IBMEC. Rio de Janeiro, 2007.

Enviado: Setembro, 2019

Aprovado: Outubro, 2019. 